\title{
Caracterização molecular de plantéis de tilápia do Nilo (Oreochromis niloticus L.) em Santa Catarina, Brasil
}

\section{Molecular characterization of Nile tilapia (Oreochromis niloticus L.) in Santa Catarina, Brazil}

\author{
Gustavo Emygdio Halfen ${ }^{1 *}$, Maycon Eduardo Nicoletti ${ }^{2}$, Henrique B. Appel ${ }^{3}$ e Fernando \\ Adami Tcacenco ${ }^{2}$ \\ ${ }^{I}$ Departamento de Engenharia de Bioprocessos e Biotecnologia; Universidade Federal do Paraná; 81531-970; \\ Curitiba - PR - Brasil. ${ }^{2}$ Laboratório de Biotecnologia; Epagri; Estação Experimental de Itajaí; 88301-970; Itajaí - \\ SC - Brasil. ${ }^{3}$ Programa de Piscicultura; Epagri; Estação Experimental de Itajaí; 88301-970; Itajaí - SC - Brasil.
}

\begin{abstract}
Fishery plays an important role in the supply of food for the increasing population. Tilapia production exceeded two million tons, being the second most important group of fish worldwide. Nile tilapia (Oreochromis niloticus Linnaeus, 1758) is the most important species due to the fast growth rates and good acceptance by the consumer. Fish genetic improvement is highly based on molecular genetics, including RAPD, and the knowledge obtained in the last decades gave good results in terms of molecular marker-assisted breeding. In the present work the genetic variability of four populations of Nile tilapia was assessed using molecular techniques. Modifications in the DNA extraction protocol described by Bardakci and Skibinski (1994) were evaluated, which was followed by the application of the RAPD technique, using eight primers and twenty specimens of four tilapia lineages (Bouaké, Chitralada, GST and GIFT). The results from the PCR amplifications were evaluated using the programs NTSys and PopGen. GIFT was the most polymorphic group, with $37 \%$ of its loci showing polymorphism, and the group that presented the highest Shannon index (0,17). All primers but one (OPA-12 for the lineage Chitralada) showed bands that can be used as a diagnostic tool for lineage differentiation. The dendrogram generated with the polymorphic bands clearly separated the four populations; GIFT and Chitralada presented the highest genetic similarity (0,88), whereas GIFT and GST presented the highest genetic distance $(0,23)$.
\end{abstract}

Key-words: Molecular characterization, genetic similarity, genetic divergence, RAPD

\section{INTRODUÇÃO}

O Brasil é hoje um dos países que mais cresce em produção de pescado pela aquicultura. Em 2006 teve um aumento de $6,4 \%$ na sua produção, crescimento superior ao mundial (IBAMA, 2008). Segundo IBAMA (2008), a região Sul contribui com a maior parcela na produção nacional de pescado com 32,9\%. Santa Catarina alcançou o primeiro lugar na produção de pescado nacional em 2006, ultrapassando o estado do Pará.

Dentre a produção de pescado, destaca-se o cultivo de tilápias, sendo o segundo maior grupo de peixes produzidos pela aquicultura, ficando apenas atrás das carpas. A produção de tilápia no estado de Santa Catarina quadruplicou entre 1996 e 2002, tornando-se a espécie mais criada no estado (Boll et al., 2004).

As tilápias pertencem à família Cichlidae, já tendo sido identificadas aproximadamente 70 espécies. A espécie mais cultivada, representando $80 \%$ da produção total de tilápias é a tilápia do Nilo (Oreochromis niloticus Linnaeus, 1758) devido às suas características zootécnicas vantajosas (Kubitza, 2005). Esta espécie é formada por linhagens de diferentes locais de origem. A linhagem de tilápia do Nilo denominada Bouaké é originária da Costa do Marfim, região oeste da África; a linhagem Chitralada teve origem no Egito, foi levada para o Japão e posteriormente para a Tailândia, passando assim por várias 
gerações de cultivo e domesticação (Moreira, 1999; Kubitza, 2000).

A primeira linhagem introduzida no Brasil foi a Bouaké, no estado do Ceará, importada da Costa do Marfim - África, no ano de 1971, através do DNOCS (Departamento Nacional de Obras Contra as Secas) em Pentecostes (Castagnolli, 1992; Zimmermann, 1999). A linhagem Chitralada foi importada da Tailândia em 1996, para Londrina, Paraná. Esta linhagem foi domesticada desde a década de 1940 no Japão e depois na Tailândia (Zimmermann, 1999).

Em 2002 foi introduzida uma nova linhagem de tilápia do Nilo no Brasil, a GST Genomar Supreme Tilápia (Zimmermann, 2003), pela Piscicultura Aquabel, proveniente de uma empresa norueguesa denominada GENOMAR, a qual, desde 1999 vem desenvolvendo um programa de melhoramento genético (Massago, 2007). A partir de 2005 a linhagem GIFT (Genetically Improved Farmed Tilapia) da Malásia foi introduzida no Brasil pelo Departamento de Zootecnia da Universidade Estadual de Maringá, com o apoio do Instituto de Tecnologia de Maringá e financiamento da Secretaria Especial de Aqüicultura e Pesca (SEAP - PR). A linhagem GIFT foi desenvolvida inicialmente pelo ICLARM (International Center for Living Aquatic Resources Management), hoje denominado WorldFish Center, a partir de quatro linhagens africanas selvagens e quatro linhagens domesticadas na Ásia. A origem da GST e da GIFT é a mesma, entretanto após 1999, o desenvolvimento das duas ocorreu de forma independente uma da outra (Massago, 2007).

No caso de Santa Catarina, onde são desenvolvidas ações de pesquisa envolvendo o melhoramento genético da tilápia do Nilo, está sendo criado um Banco de Germoplasma dessa espécie, com espécimes das linhagens Bouaké, Chitralada, GST e GIFT advindos de diversos centros de pesquisa e produção tais como o Grupo de Pesquisa PeixeGen, do Departamento de Zootecnia da Universidade Estadual de Maringá, e de produtores de tilápia do Nilo de Santa Catarina. Até o momento nenhum estudo de caracterização molecular destas diferentes linhagens de Oreochromis niloticus em Santa Catarina foi realizado, daí a importância deste trabalho no contexto catarinense de produção de tilápia do Nilo. Baseado nisso, o objetivo deste trabalho foi à caracterização molecular e a busca por marcadores moleculares para populações de tilápia do Nilo
(Oreochromis niloticus L.) em estudo, através das técnicas RAPD, para suporte ao programa de melhoramento genético desta espécie, visando ao sistema de cultivo intensivo na região litorânea de Santa Catarina.

\section{MATERIAL E MÉTODOS Material biológico}

Para o presente trabalho foram utilizadas quatro populações de tilápia do Nilo: (i) Bouaké, obtida do produtor Valdir Krhan do município de Pomerode (SC), que possui esta linhagem isolada em um lago em cima de um morro há mais de 20 anos; (ii) Chitralada, obtida da Fundação Municipal 25 de Julho, situada no município de Joinville (SC), importada da Tailândia em 1997; (iii) GST, obtida do produtor Vilmar Rossi, no município de Massaranduba (SC), adquirida da empresa privada Aquabel, situada em Londrina (PR), que possui direito exclusivo de comercialização desta linhagem; e (iv) GIFT, obtida do Grupo de Pesquisa PeixeGen, do Departamento de Zootecnia da Universidade Estadual de Maringá. Esses materiais formam o Núcleo Satélite de Tilápia do Nilo do Estado de Santa Catarina, parte da UMGEP - Unidade de Melhoramento Genético de Peixes da Epagri/Itajaí. Foram selecionados aleatoriamente vinte indivíduos de cada uma das populações em estudo. O material biológico usado foram amostras de nadadeira caudal de aproximadamente $2,0 \mathrm{~cm}^{2}$. As amostras de nadadeiras caudais foram retiradas nos respectivos locais de obtenção das populações, com o auxílio de uma tesoura, e preservadas a -20 ${ }^{\circ} \mathrm{C}$ em etanol $70 \%$, para posterior extração de DNA.

As análises genéticas do material biológico foram realizadas no Laboratório de Biologia Molecular da Epagri - Estação Experimental de Itajaí (EEI), localizada no município de Itajaí - SC.

\section{Extração de DNA}

Para extração de DNA das amostras de nadadeira caudal, primeiramente testou-se o protocolo descrito por Bardakci e Skibinski (1994). Para a obtenção do DNA genômico, em geral os protocolos são divididos em duas etapas principais: (i) utilização de detergentes para a lise de membranas celulares, permitindo a exposição do DNA; e (ii) tratamentos químicos e enzimáticos para purificar o material genômico, eliminando assim contaminantes como RNA, polissacarídeos e proteínas. No tocante à primeira etapa, o protocolo 
descrito por Bardakci e Skibinski (1994), submete o material em tampão de lise a $50^{\circ} \mathrm{C}$ por 24 horas, sendo dispendioso no que se refere à energia elétrica e tempo, além de ser agressivo ao material genético. Neste sentido, a fim de estabelecer um melhor tempo para obtenção de um DNA menos degradado e mais puro, as amostras foram incubadas em microtubos com $550 \mu \mathrm{L}$ de tampão de lise $(50 \mathrm{mM}$ de Tris-HCl, $50 \mathrm{mM}$ de EDTA, $100 \mathrm{mM}$ de $\mathrm{NaCl}$ e $1 \%$ de SDS) e $200 \mu \mathrm{g} / \mathrm{mL}$ de proteinase $\mathrm{K}$, conforme protocolo original e, em seguida, foram incubadas a $50^{\circ} \mathrm{C}$ em uma estufa em cinco diferentes intervalos de tempo: 1, 4, 8, 16 e 24 horas, com seis repetições por tratamento. Após este procedimento, iniciou-se a etapa de purificação. O DNA foi purificado com duas extrações com fenol e três extrações com clorofórmio. O material obtido foi precipitado com 2,5 volumes de etanol absoluto e 0,1 volume de acetato de sódio em relação ao volume recuperado, e incubado por duas horas a $-20{ }^{\circ} \mathrm{C}$. Em seguida o DNA foi lavado com $2,0 \mathrm{~mL}$ de etanol $70 \%$ e seco por uma hora em câmara de fluxo, sendo em seguida ressuspendido em $100 \mu \mathrm{L}$ de tampão TE (10 $\mathrm{mM}$ de Tris pH 8,0 e $1 \mathrm{mM}$ de EDTA) e tratado com $30 \mu \mathrm{g} / \mathrm{mL}$ de RNAse, incubado novamente por uma hora a $37{ }^{\circ} \mathrm{C}$, e em seguida conservado a $-20{ }^{\circ} \mathrm{C}$.

A integridade do DNA extraído foi verificada em gel de agarose $0,8 \%$ revelado com brometo de etídio, sendo a eletroforese conduzida a $60 \mathrm{~V}$ por 45 minutos em cuba horizontal usando tampão TAE 1X. Em seguida o DNA foi quantificado em triplicatas em espectrofotômetro $\mathrm{Femto}^{\circledR}$, no comprimento de onda $260 \mathrm{~nm}\left(\mathrm{~A}_{260}\right)$, e sua pureza foi determinada pela razão das absorbâncias 260 $\mathrm{nm}$ e $280 \mathrm{~nm}$, sendo as razões médias recomendadas para um DNA puro entre 1,8 e 2,0 (Brasileiro, 1998). Foram utilizadas seis repetições por tratamento. Os dados de quantificação e qualidade foram submetidos a analise de variância. Após a análise do teste de incubação do material em tampão de lise sob diferentes intervalos de tempo a $50{ }^{\circ} \mathrm{C}$ notou-se que a técnica comumente resultava em elevadas concentrações de DNA, porém muitas vezes este se encontrava degradado devido ao excesso de produtos agressivos usados na purificação da amostra, já que são feitas duas extrações com fenol:clorofórmio (1:1) e uma com clorofórmio. Em contrapartida, a metodologia descrita por Wasko et al. (2003) utiliza apenas uma extração com uma solução à base de fenol:clorofórmio:álcool isoamílico (25:24:1).
Outra técnica é a descrita por Miller et al. (1988), que utiliza apenas uma extração com uma solução de $100 \mu \mathrm{L}$ de $\mathrm{NaCl} 6 \mathrm{M}$. Com o objetivo de diminuir o uso de substâncias agressivas utilizadas no protocolo descrito por Miller et al. (1988) e por Bardakci e Skibinski (1994), com base nas técnicas descritas por Wasko et al. (2003), a extração de DNA foi repetida, onde os passos iniciais das extrações foram baseadas no protocolo de Bardakci e Skibinski (1994), e por ocasião da purificação, os tratamentos foram divididos em três grupos, sendo um baseado na técnica de Bardakci e Skibinski (1994), outro na metodologia de Wasko et al. (2003), e o terceiro na metodologia de Miller et al. (1988).

A análise da integridade do DNA extraído e sua quantificação foram feitas da mesma forma que do teste anterior, porém neste a quantificação foi realizada em duplicatas. Os dados foram submetidos à análise de variância.

Em seguida, para o presente trabalho foi utilizado o protocolo descrito por Bardakci e Skibinski (1994), modificado por Halfen et al. (2008 a, b). Os fragmentos de nadadeira caudal de aproximadamente $2,0 \mathrm{~cm}^{2}$ preservados a $-20{ }^{\circ} \mathrm{C} \mathrm{em}$ etanol $70 \%$ foram colocados em microtubos com $550 \mu \mathrm{L}$ de tampão de lise $(50 \mathrm{mM}$ de Tris- $\mathrm{HCl}, 50$ $\mathrm{mM}$ de EDTA, $100 \mathrm{mM}$ de $\mathrm{NaCl}$ e $1 \%$ de SDS) e $200 \mu \mathrm{g} / \mathrm{mL}$ de proteinase $\mathrm{K}$ e, em seguida, incubados a $50^{\circ} \mathrm{C} \mathrm{em}$ uma estufa por quatro horas. Posteriormente, o DNA foi purificado através de duas extrações com fenol e três extrações com clorofórmio. O DNA obtido foi precipitado com 2,5 volumes de etanol absoluto e 0,1 volume de acetato de sódio em relação ao volume recuperado, e incubado por duas horas a $-20{ }^{\circ} \mathrm{C}$. Em seguida o DNA foi lavado com $2,0 \mathrm{~mL}$ de etanol $70 \%$, ressuspendido em $100 \mu \mathrm{L}$ de tampão TE $(10 \mathrm{mM}$ de Tris pH 8,0 e $1 \mathrm{mM}$ de EDTA) e tratado com $30 \mu \mathrm{g} / \mathrm{mL}$ de RNAse, sendo incubado por uma hora a $37^{\circ} \mathrm{C}$, e em seguida, conservado a $-20^{\circ} \mathrm{C}$. O DNA isolado foi visualizado por eletroforese e quantificado no espectrofotômetro $\mathrm{Femto}^{\circledR}$ como nos testes anteriores.

\section{Amplificação de DNA genômico}

Com DNA de boa qualidade, foi aplicada a técnica de RAPD. As reações foram realizadas em microtubos para PCR (volume 0,2 mL) em um volume total de $40 \mu \mathrm{L}$, contendo tampão Taq Buffer 1X, 1,5 mM de $\mathrm{MgCl}_{2}, 1,0 \mu \mathrm{M}$ de iniciadores, 0,6 mM de dNTPs, 2,5 U de Taq DNA polimerase (Fermentas ${ }^{\circledR}$ ), $50 \mathrm{ng}$ de DNA 
genômico e $5 \%$ de dimetilsulfóxido (DMSO), este último usado como otimizador de PCR por proporcionar auxilio na desnaturação de seqüências ricas em GC (Franckman et al., 1998). Os iniciadores testados foram: A-01 (CAG GCC CTTC), A-09 (GGG TAA CGCC), A-11 (CAA TCG CCGT), A-12 (TCG GCG ATAG), A-14 (TCT GTG CTGG) (Povh et al., 2005); OPA-02 (TGC CGA GCTG), OPA-03 (AGT CAG CCAC) e OPA-20 (GTT GCG ATCC), (Massago, 2007). A metodologia de escolha dos iniciadores foi baseada no número de lócus polimórficos e por serem bons marcadores moleculares para diferenciação de linhagens de $O$. niloticus, segundo a literatura.

O DNA foi amplificado em um termociclador PTC-100 (MJ Research Inc) através da seguinte programação: $95^{\circ} \mathrm{C}$ por 5 minutos de desnaturação inicial; 45 ciclos de $92{ }^{\circ} \mathrm{C}$ por 1 minuto de desnaturação, $35^{\circ} \mathrm{C}$ por 1 minuto para anelamento dos iniciadores e $72{ }^{\circ} \mathrm{C}$ por 2 minutos de extensão; e $72{ }^{\circ} \mathrm{C}$ por 7 minutos de extensão final.

Os produtos obtidos pela técnica RAPD, junto com os marcadores $1 \mathrm{~Kb}$ e $100 \mathrm{pb}$ (Fermentas ${ }^{\circledR}$ ), foram submetidos à separação eletroforética em gel de agarose $1,2 \%$ em uma cuba horizontal a 70 $\mathrm{V}$ contendo tampão TBE $1 \mathrm{X}$, durante quatro horas e trinta minutos e corados com brometo de etídio. Os fragmentos de DNA foram visualizados por meio de um transiluminador ultravioleta (Vilber Lourmat $^{\circledR}$ ) e fotodocumentados.

\section{Análise dos padrões de fragmentos}

A análise dos padrões de fragmentos amplificados foi realizada pela comparação do perfil eletroforético obtido para cada indivíduo. O tamanho dos fragmentos foi estimado em comparação com o padrão dos marcadores de 100 pb e $1 \mathrm{~Kb} \quad\left(\right.$ Fermentas $\left.^{\circledR}\right)$. A avaliação da variabilidade genética foi anotada através de bandas de DNA amplificadas nos diferentes genótipos, onde receberam as seguintes codificações: 0 (ausência) e 1 (presença); somente bandas fortes e consistentes foram consideradas. Assim, por meio do programa NTSYS 2.1 (Rohlf, 1989), foi gerada uma matriz binária que resultou em uma matriz de similaridade genética de cada grupo, utilizando-se o coeficiente de Jaccard. A construção do dendograma para representar graficamente o padrão de diversidade genética dos indivíduos foi realizada pelo método de agrupamento UPGMA.
O programa PopGen 1.3 (Yeh et al., 1999) foi utilizado para as análises estatísticas, na obtenção do número de alelos observados, frequência alélica, heterozigosidade observada e esperada, distância genética e identidade genética entre os plantéis. Os dados também foram escrutinados à procura de marcadores ligados a diferenciação das linhagens estudadas.

\section{RESULTADOS E DISCUSSÃO \\ Extração de DNA}

Em relação aos testes com os diferentes intervalos de tempo de ação do tampão lise (Barcacki e Skibinski, 1994), pela análise do gel da corrida eletroforética, observou-se que os tratamentos de 1 $\mathrm{h}, 4 \mathrm{~h}$ e $8 \mathrm{~h}$ foram os melhores em relação à visualização das bandas no gel, quando comparados aos tratamentos de $16 \mathrm{~h}$ e $24 \mathrm{~h}$ (Figura 1). Dentre os três melhores, o tratamento de $4 \mathrm{~h}$ produziu bandas mais definidas e consistentes. As concentrações de DNA obtidas nos cinco tratamentos foram $\left(\mu \mathrm{g} \mathrm{mL}^{-1}\right): 781,570,659,853 \mathrm{e}$ 952, respectivamente para os tratamentos $1,4,8$, 16 e $24 \mathrm{~h}$. Estatisticamente, não houve diferenças significativas entre os tratamentos. No tocante aos dados de pureza do DNA, foram verificados os seguintes resultados (relação $\mathrm{A}_{260} / \mathrm{A}_{280}$ ): 2,6, 2,3, 2,7, 2,9 e 2,7, sem diferenças estatísticas entre eles. Comparando os dados quantitativos e qualitativos, conclui-se que o tratamento de 4 h é o mais indicado, por apresentar tempo relativamente curto, concentração aceitável, e melhor grau de pureza e de integridade do DNA, confirmados pela visualização em gel.

No tocante ao teste de diminuição do uso de substâncias agressivas utilizadas no protocolo descrito por Bardakci e Skibinski (1994), baseado nas técnicas descritas por Wasko et al., (2003) e por Miller et al., (1988), não foram observadas diferenças quanto à integridade do material genético entre os três tratamentos (Figura 2). No entanto notou-se uma menor consistência das bandas no protocolo de Bardakci e Skibinski (1994), refletindo a menor concentração de DNA, esta confirmada pela quantificação em espectrofotometria. Estatisticamente, os tratamentos não mostraram diferenças significativas nos parâmetros avaliados. Analisando de forma crítica, as médias de concentração de DNA indicam que a metodologia descrita por Bardakci e Skibinski (1994), apresentou menor concentração de material genômico quando comparada aos demais 
protocolos, porém com mais alto grau de pureza (Tabela 1). Este resultado é consequência do maior número de etapas de purificação, o que acarreta perda de material genético. Os demais protocolos, por possuírem métodos menos agressivos, resultaram um grau de pureza menor e um DNA menos degradado.

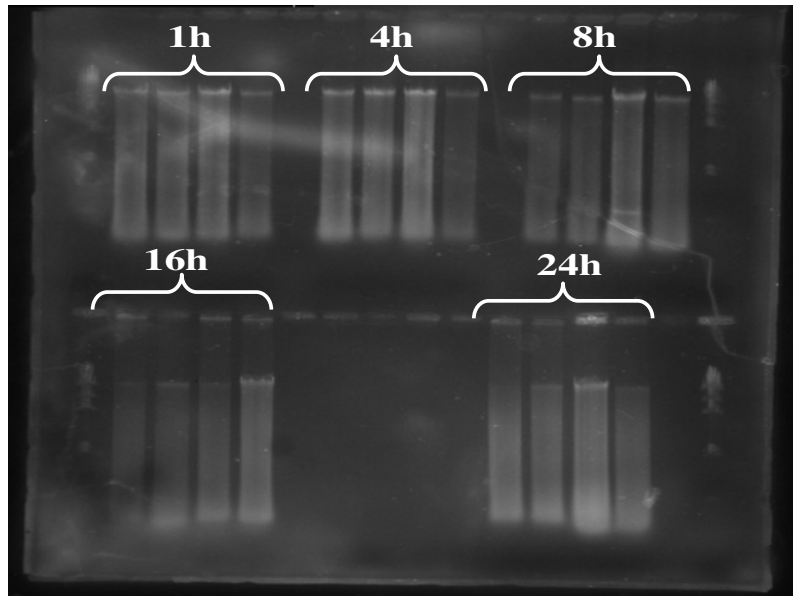

Figura 1 - Gel de agarose com os resultados do teste de diferentes intervalos de tempo de ação do tampão de lise (Bardakci e Skibinski, 1994); 1, 4, 8, 16 e 24 horas.

Tabela 1. Dados de concentração e qualidade de DNA genômico pelos três tratamentos (Miller et al., 1988; Wasko et al., 2003; Bardacki e Skibinski, 1994) de teste de diminuição de substâncias agressivas ao material genômico.

\begin{tabular}{cccc}
\hline & Tratamentos & \\
\hline \multirow{2}{*}{$\begin{array}{c}\text { Concentração } \\
(\mu \mathrm{g} / \mathrm{mL})\end{array}$} & Bardakci e Skibinski & Wasko & Miller \\
\cline { 2 - 4 } & 275,83 & 457,92 & 395,83 \\
\hline Coeficiente de variação $=43 \%$; ANOVA = não significativo. & & 2,70 \\
\hline $\begin{array}{c}\text { Qualidade } \\
\text { (Relação A260/A280) }\end{array}$ & 2,15 & 2,35 & \\
\hline
\end{tabular}

Coeficiente de variação $=12,7 \%$; ANOVA = não significativo.

\section{Análise do padrão de fragmentos}

Quatro iniciadores (A-01, OPA-02, A-11, A-12) foram escolhidos para a análise do padrão dos fragmentos, por apresentarem bandas mais definidas e consistentes. Foram obtidos 98 locos, 59 dos quais foram polimórficos, ou seja, $60 \%$ dos locos apresentaram polimorfismo; esta análise é confirmada com o índice de diferenciação Gst obtido, que foi 0,600. Massago (2007), analisando as mesmas linhagens do presente trabalho, obteve 81 locos, dos quais $42 \%$ polimórficos. Povh et al. (2005), analisando duas diferentes linhagens de Bouaké e duas diferentes linhagens de Chitralada, obtiveram 90 locos com $50 \%$ de polimorfismo. Lopera Barrero et al. (2006), com um total de 87 locos, obteve $70 \%$ de locos polimórficos para outra espécie. Devido à técnica RAPD ser muito sensível a variações, é normal a porcentagem de locos polimórficos variarem entre diferentes trabalhos.

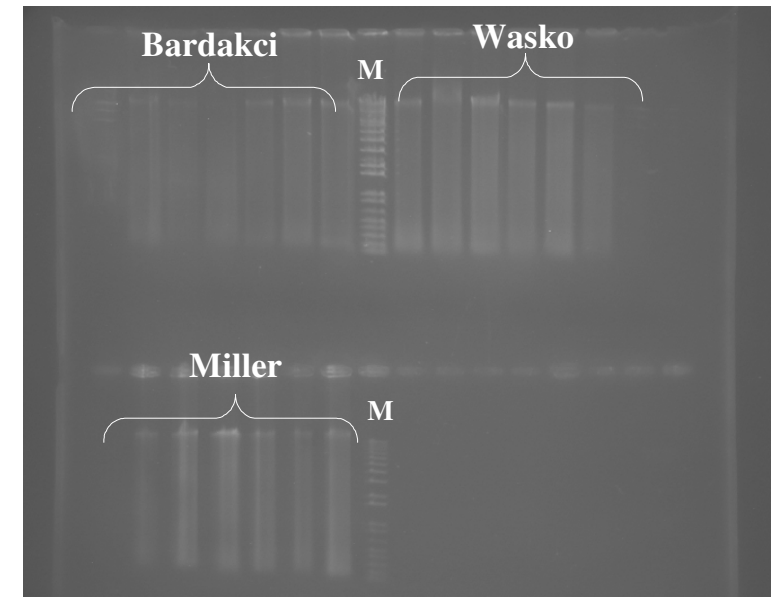

Figura 2 - Gel de agarose com os três tratamentos testados no teste de diminuição de substâncias agressivas ao DNA genômico do protocolo de extração de DNA descrito por Bardacki e Skibinski (1994).

Em relação às linhagens, o maior polimorfismo foi encontrado pela linhagem GIFT (37\%), que sugere maior variação genética desta espécie em relação 
às demais, sendo a Chitralada a menos polimórfica (21\%). O maior polimorfismo é evidenciado também pelo índice de Shannon, que indica a variabilidade genética intrapopulacional; o da linhagem GIFT $(0,17)$, foi maior do que das linhagens GST $(0,12)$, Bouaké $(0,10)$ e Chitralada $(0,09)$ (Tabela 2).

A linhagem GIFT, após ter passado pelo processo de melhoramento genético, não sofreu uma perda significativa da variabilidade genética neste procedimento, apesar do controle efetivo e intencional de seleção (Lupchinski Jr, 2007), fato evidenciado pelo alto valor de polimorfismo (37\%). A linhagem Bouaké apresentou maior porcentagem de locos polimórficos em relação à Chitralada (Tabela 2). Estes resultados estão de acordo com Massago (2007) que encontrou maior polimorfismo na linhagem Bouaké (26\%),

Tabela 2. Índice de Shannon e porcentagem de locos polimórficos obtidos pelo programa Popgen

\begin{tabular}{lcc}
\hline Linhagem & $\begin{array}{c}\text { Índice de } \\
\text { Shannon }\end{array}$ & $\begin{array}{c}\text { \% de locos } \\
\text { polimórficos }\end{array}$ \\
\hline Bouaké & 0,10 & 23 \\
Chitralada & 0,09 & 21 \\
GST & 0,12 & 26 \\
GIFT & 0,17 & 37 \\
\hline
\end{tabular}

Todos os iniciadores apresentaram bandas exclusivas para todas as populações, com exceção do iniciador A-12 que não apresentou bandas exclusivas para a população Chitralada (Tabela 3). Segundo Povh et al. (2005), estas bandas exclusivas podem ser utilizadas para identificação destas linhagens, com o desenho de iniciadores específicos (SCAR - Sequence Characterized Amplified Region), tornando-se marcadores para estas linhagens. A caracterização genética em populações de tilápia representa um importante comparada a Chitralada (20\%). Atribui-se este resultado ao baixo número de iniciadores usados na análise destas populações, onde o iniciador A11 não teve locos polimórficos para a população Chitralada, dando esta como idêntica. Povh et al. (2005) e Lupchinski Jr (2007), obtiveram resultados contrários a estes; Povh et al., (2005) obtiveram menor número de locos polimórficos para a linhagem Bouaké (19\%) comparada a Chitralada (33\%). Segundo o mesmo autor, o menor grau de polimorfismo da linhagem Bouaké em relação à Chitralada, pode ser explicado pelo tempo de introdução relativo às duas linhagens no país, 1971 e 1996, respectivamente, assim uma linhagem mais antiga tende a sofrer maiores efeitos de consanguinidade e estrangulamento genético.

recurso para o melhoramento do cultivo desta espécie (Mather, 2001).

O dendrograma obtido com o agrupamento UPGMA pelo coeficiente de Jaccard utilizando o programa NTSYS apresentou separação clara das linhagens de tilápia do Nilo (Figura 4). Lupchinski Jr (2007), utilizando marcadores RAPD com 25 indivíduos, observou agrupamento de acordo com cada linhagem, porém não absoluto. Povh et al. (2005), utilizando a mesma técnica também com o emprego do coeficiente de Jaccard, analisou a diversidade das linhagens Bouaké e Chitralada, obtendo uma separação clara no seu dendograma. Conforme o dendrograma obtido, as populações GIFT e Chitralada foram as mais próximas geneticamente, corroborando os resultados de Massago (2007). A linhagem GST foi a mais afastada geneticamente. Este resultado não era esperado, pois as linhagens GST e GIFT possuem a mesma origem evolutiva, e também não equivalendo com os dados de Massago (2007), que obteve a linhagem Bouaké como a mais afastada.

Tabela 3. Tamanho em pares de base (pb) das bandas amplificadas pelos 4 iniciadores que são marcadoras exclusivas para cada população em estudo.

\begin{tabular}{ccccc}
\hline & OPA-01 & OPA-02 & OPA-11 & OPA-12 \\
\hline Bouaké & 850,490 & 1760,250 & 300 & 490,269 \\
Chitralada & 1250 & 1500 & 650 & - \\
GST & 1200,880 & 1550 & $1750,1300,390$ & 515,390 \\
GIFT & $1550,1350,1000$ & 600,450 & 610 & 1000 \\
\hline
\end{tabular}


Tanto o dendrograma como os índices de distância e identidade genética (NEI, 1978) deram resultados congruentes (Tabela 4), onde as linhagens GIFT e Chitralada tiveram a maior identidade genética $(0,88)$ e as linhagens GIFT e GST tiveram a maior distância genética $(0,23)$.

Tabela 4. Identidade Genética de Nei (1978) entre as linhagens e abaixo da diagonal Distancia Genética de Nei (1978) entre as linhagens, obtidas pelo programa Popgen.

\begin{tabular}{ccccc}
\hline & Bouaké & GIFT & Chitralada & GST \\
\hline Bouaké & - & 0,83 & 0,84 & 0,82 \\
GIFT & 0,19 & - & 0,88 & 0,80 \\
Chitralada & 0,17 & 0,13 & - & 0,82 \\
GST & 0,20 & 0,23 & 0,20 & - \\
\hline
\end{tabular}

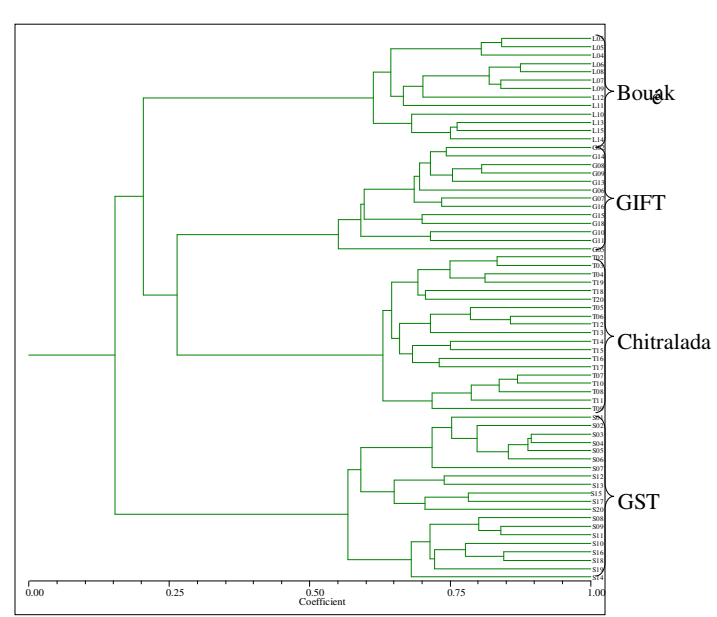

Figura 4 - Dendograma obtido com o agrupamento UPGMA, pelo coeficiente de Jaccard, utilizando o programa NTSYS, para as linhagens Bouaké, Chitralada, GST e GIFT.

\section{CONCLUSÕES E PERSPECTIVAS}

As otimizações no protocolo de extração de DNA descrito por Bardakci e Skibinski (1994) tornaram a técnica menos laboriosa e mais econômica, diminuindo o tempo de incubação do tampão de lise de 24 horas para 4 horas. Em relação à diminuição do uso de substâncias agressivas ao DNA, baseado nos protocolos descritos por Wasko et al. (2003) e Miller et al. (1988), recomenda-se uma combinação entre as três técnicas visando a um protocolo menos trabalhoso e que preserve a integridade do DNA, dependendo também da quantidade de amostras disponíveis, visando um material genético mais puro ou mais concentrado.

A técnica RAPD foi eficaz para a caracterização genética das diferentes linhagens de $O$. niloticus (Bouaké, Chitralada, GST e GIFT). Todos os oito iniciadores escolhidos já haviam sido usados em análises genéticas de $O$. niloticus (Povh et al., 2005; Lupchinski Jr., 2007; Massago, 2007), porém no presente trabalho, somente quatro iniciadores foram selecionados para a análise do padrão de fragmentos amplificados. Apesar disso, todos os resultados corroboraram aqueles citados na literatura, com exceção do iniciador OPA-11 que não apresentou locos polimórficos para a população Chitralada, resultando em todos os indivíduos desta como idênticos. Sugere-se que a técnica RAPD seja repetida com um maior número de iniciadores, ponderando assim o peso de cada um, e dando também uma maior consistência aos dados, confirmando se estes são os mais apropriados para análise genética de $O$. niloticus, e para concretizar os resultados aqui obtidos.

\section{RESUMO}

Com o aumento da demanda de produção de alimentos na atualidade, a aquicultura tem um papel promissor na contribuição da oferta de alimentos. Merece destaque o cultivo de tilápias, cuja produção mundial ultrapassou dois milhões de toneladas, sendo o segundo maior grupo de peixes produzidos pela aquicultura, ficando apenas atrás das carpas. A espécie mais cultivada é a tilápia do Nilo (Oreochromis niloticus Linnaeus, 1758), devido principalmente à alta prolificidade, crescimento rápido e boa aceitação do consumidor, características buscadas com o melhoramento genético. $\mathrm{O}$ melhoramento genético de peixes cultivados tem tido como uma de suas bases os progressos obtidos na área da genética molecular. O conjunto de métodos desenvolvidos nessa ciência nas últimas décadas possibilitou, com sua incorporação na aqüicultura, ganhos consideráveis, particularmente quando aplicados no melhoramento genético assistido por marcadores moleculares. A diversidade genética em populações de tilápias pode ser determinada através de marcadores moleculares como do tipo RAPD. O presente trabalho visou ao levantamento da variabilidade genética existente entre as quatro populações de tilápia do Nilo que formam o Núcleo Satélite de Tilápia do Nilo do Estado de Santa Catarina, parte da UMGEP - Unidade de Melhoramento Genético de Peixes da Epagri/Itajaí, e à busca de marcadores moleculares de identificação das diferentes linhagens da espécie, para aplicação no 
melhoramento genético assistido por marcadores. Para tanto, foram conduzidos experimentos de otimização do protocolo de extração de DNA (Bardakci e Skibinski, 1994), obtendo assim DNA de boa qualidade. Em seguida foram selecionados 20 indivíduos de cada uma das linhagens (Bouaké, Chitralada, GST e GIFT), e foram testados oito iniciadores de RAPD. Posteriormente os fragmentos amplificados foram submetidos à análise pelos programas NTSys e Popgen. Em análise intrapopulacional, a linhagem GIFT foi a mais polimórfica em relação às outras, obtendo maior numero de lócus polimórficos $(37 \%)$ e o maior índice de Shannon $(0,17)$. Todos os iniciadores apresentaram bandas exclusivas podendo ser usadas como marcadores moleculares na diferenciação das linhagens, com exceção do iniciador OPA-12 para a população Chitralada. O dendrograma obtido com o agrupamento UPGMA apresentou separação clara das linhagens, agrupando-as conforme os índices genéticos, onde as linhagens GIFT e Chitralada tiveram a maior identidade genética $(0,88)$ e as linhagens GIFT e GST tiveram as maiores distâncias genéticas $(0,23)$.

Palavras-chave: Caracterização molecular, Oreochromis niloticus, divergência genética

\section{REFERÊNCIAS}

Bardakci, F. e Skibinski, D. O. F. (1994), Aplication of the RAPD technique in tilapia fish: species and subspecies identification. Heredity, 73, 117-132.

Boll, M. G.; Roczansky, M.; Gazolla, A. C. (2004), A produção de peixes cultivados na região Litoral norte de Santa Catarina, Brasil (19962002): Resultados e tendências. In: CONGRESSO DA SOCIEDADE BRASILEIRA DE AQÜICULTURA E BIOLOGIA AQUÁTICA, I, Vitória - ES. Anais. 361p.

Brasileiro, A. C. M. (1998), Neomicina Fosfotransferase II (NPT II). In: Brasileiro, A. C. M e Carneiro, V. T. C. Manual de Transformação Genética de Plantas, EMBRAPA-SPI/EMBRAPACENARGEN, Brasília, Brazil, 143-154.

Castagnolli, N. (1992), Piscicultura de água doce. Jaboticabal: FUNEP, 189p.

Frackman S, Kobs G, Simpson D, Storts D (1998), Betaine and DMSO: Enhancing Agents for PCR. Promega Notes, 27p.

Halfen, G. E.; Nicoletti, M. E.; Appel, H. B.; Tcacenco, F. A. (2008a), Otimização na extração de DNA de tilápia do Nilo (Oreochromis niloticus): período de incubação versus qualidade e concentração de DNA. In: Aquaciência, 2008, Maringá, PR. CD-ROOM.

Halfen, G. E.; Nicoletti, M. E.; Appel, H. B.; Tcacenco, F. A. (2008b), Modificações no protocolo de extração de DNA de tilápia do Nilo (Oreochromis niloticus) visando à integridade do material genético. In: Aquaciência, 2008, Maringá, PR. CD-ROOM.

IBAMA, (2008), Estatística de Pesca 2006 Brasil: Grande regiões e unidades da federação. Brasília, 174p.

Kubitza, F. (2000), Tilápia: Tecnologia e planejamento na produção comercial. Jundiaí, 285p.

Kubitza, F. (2005), Tilápia em água salobra: uma boa alternativa de cultivo. Panorama $d a$ Aquicultura, 15, 14-18.

Lopera-Barrero, N. M.; Ribeiro, R. P.; Sirol, R. N.; Povh, J. A.; Gomes, P. C.; Vargas, L.; Streit Jr., D. P. (2006), Genetic diversity in piracanjuba populations (Brycon orbignyanus) with the RAPD (Random Amplified Polimorphic DNA) markers. Journal of Animal Science, 84, 170-170.

Lupchinski Jr, E. Avaliação da composição genética de linhagens de tilápia do Nilo (oreochromis niloticus) e de gerações $\mathrm{G}_{0}$ e $\mathrm{F}_{1}$ da linhagem GIFT. Tese (Doutorado em Zootecnia) Universidade Estadual de Maringá, 2007.

Massago, H. Desempenho de alevinos de quatro linhagens da tilápia do Nilo (Oreochromis niloticus) e análise da variabilidade genética pelos marcadores RAPD. Dissertação (Mestrado em Aquicultura) - Universidade Estadual Paulista, 2007.

Mather, P. B. (2001), Overview of fish genetics research at Queensland University of Technology, 133-139. In: Gupta, M. V. e Acosta, B. O. Fish genetics research in member countries and institutions of the International Network on Genetics in Aquaculture. Brisbane: ICLARM, 64179. 
Miller, S. A.; Dikes, D. D.; Pololesky, H. F. (1988), A simple salting out procedure of extracting DNA from human nucleated cells. Nucleic Acids Research, 16, 12-15.

Moreira, H. L. M. Análise da estrutura de populações e diversidade genética de estoques de reprodutores de tilápia do Nilo (Oreochromis niloticus) estimadas por microssatélite. Tese (Doutorado em Genética e Biologia Molecular) Universidade Federal do Rio Grande do Sul, 1999.

Nei, M. (1978), Estimation of average heterozygosity and genetic distance from a small number of individuals. Genetics, 89, 583-590.

Povh, J. A.; Moreira, H. L. M.; Ribeiro, R. P.; Prioli, A. J.; Vargas, L.; Blanck, D. V.; Gasparino, E.; Streit Jr, D. P. (2005), Estimativa da variabilidade genética em linhagens de tilápia do Nilo (Oreochromis niloticus) com a técnica de RAPD. Acta Scientiarum Animal Sciences, 27, 110.

Rohlf, F. J. NTSYS-Pc: Numerical taxonomy and multivariate analysis system. New York: Exeter Publishers, 1989.
Wasko, A. P.; Martins, C.; Oliveira, C.; Foresti, F. (2003), Non-destructive genetic sampling in fish. An improved method for DNA extraction from fish fins and scales. Hereditas, 138, 161-165, 2003.

Yeh, F. C.; Boyle, T. Y. Z.; Xiyan, J. M. (1999), PopGene Version 131: Microsoft Window-based freeware for population genetic analysis. Edmonton, AB: University of Alberta and Center for International Forestry Research, 29p.

Zimmermann, S. (1999), Incubação artificial: Técnica permite a produção de tilápias do Nilo geneticamente superiores. Panorama $d a$ Aquicultura, 9, 15-21.

Zimmermann, S. (2003), Um moderno instrumental genético no melhoramento e na rastreabilidade de tilápias nilóticas. Panorama da Aquicultura, 13, 69p. 